ORIGINAL ARTICLE

\title{
Thyroid Disorders in Pregnancy and Prevalence of Subclinical Hypothyroidism in Recurrent Early Pregnancy Losses
}

\author{
MEHWISH YOUNUS ${ }^{1}$, UROOJ YASIR KHAN ${ }^{2}$, UROOJ NAZ ${ }^{3}$, ARUNA KUMARI HIRA ${ }^{4}$, SANA SHAHMIR ${ }^{5}$, \\ MAHWISH SHAH ${ }^{6}$ \\ ${ }^{1}$ Consultant Gynaecologist, Resident Medical Officer (RMO) Gynea \& Obs Civil Hospital, Karachi \\ ${ }^{2}$ Consultant Gynaecologist, Dow University Hospital, Karachi \\ ${ }^{3}$ Senior Registrar, Gynae \& Obs Civil Hospital, Karachi \\ ${ }^{4}$ Senior Registrar, Gynae Unit 1 Civil Hospital/ Dow University of Health Sciences, Karachi \\ ${ }^{5}$ Resident Medical Officer (RMO) Gynea \& Obs department, Civil hospital, Karachi \\ ${ }^{6}$ Senior Medical Officer, Gynae \& Obs Unit1 Civil Hospital/ Dow University of Health Sciences, Karachi \\ Corresponding Author: Dr Mehwish Younus, Email: dr.mehwishyounus87@gmail.com, Cell No: +923082832413
}

\begin{abstract}
Objective: Determine the frequency of hypothyroidism in recurrent pregnancy loss.

Study Design: This is cross sectional.

Place and Duration of Study: This study was conducted at Obstetrics and Gynaecology department of Dow Medical University \& Hospital, Ojha Campus, Karachi, from $7^{\text {th }}$ July 2018 to $6^{\text {th }}$ July 2019.

Methodology: This study was conducted on 83 patients. Detailed history was taken from all the patients with special regard to demographics like age, parity and recurrent pregnancy loss. A $3 \mathrm{ml}$ venous blood was drawn by the staff on duty and sent to institutional laboratory for TSH and free T4 level. TSH values more than $4.5 \mu \mathrm{IU} / \mathrm{L}$ and normal free T4 level (0.7 to $1,8 \mathrm{ng} / \mathrm{ml})$ were considered as hypothyroidism. All pregnant female was between age 20-35 years with $>6$ months gestational age and history of parity 3 and gravida 4 were included in the study. Exclusion criteria were known case of hypothyroidism or history of taking medication for hypothyroidism, history of Hypertension and DM.

Results: This study was conducted on 83 patients. There was wide variation of age ranging from a minimum of 20 years to 35 years. The mean age was $28.4+4.49$ years. Mostly patients were parity 3 and gravid 4 in $55(66.26 \%)$ cases followed by parity 4 and gravid 4 in 28(33.73\%) cases. Gestational age was measured on ultrasound ranging from 8 weeks to 22 weeks. The mean gestational age was $14.20 \pm 4.71$ years. Patient's thyroid profile mean Thyroid-stimulating hormone (TSH) level was $2.39+1.66 \mathrm{mU} / \mathrm{L}$, mean free T4 was $17.23+6.41 \mathrm{nmol} / \mathrm{L}$ and mean free T3 was $4.87+1.18 \mu \mathrm{mol} / \mathrm{L}$. Observed hypothyroidism was in $11(13.3 \%)$ cases while rest of $72(86.7 \%)$ cases within normal range.

Conclusion: We concluded that hypothyroidism is problem in recurrent pregnancy loss. $11(13.3 \%)$ cases Frequency of hypothyroidism in women with pregnancy, the possible role of thyroid functional disorders in etiology of at least some part of recurrent pregnancy loss, had emphasized the importance of thyroid functions tests screening as routine in all pregnancies.

Keywords: Thyroid disease, Pregnancy outcome, Hypothyroidism.
\end{abstract}

\section{INTRODUCTION}

Pregnancy is a phase in which the mother and the foetus are put under considerable physiological stress at best ${ }^{1}$. Recurrent pregnancy loss (RPL). Before 20 weeks of pregnancy, three or more consecutive, spontaneous pregnancy losses. Pregnancy loss is the most frequent consequence of 15-20 percent of clinically diagnosed pregnancies in the first quarter ${ }^{2}$.

Thyroid problems are the most frequent ailments in reproductive age women. They are the most prevalent endocrine problem that makes pregnancy complicated. Hypothyroidism in women diagnosed before pregnancy is $1 \%$. Maternal and foetal problems in this cohort were shown to be higher ${ }^{3}$. In the study by Amit R Barapatre, hypothyroid individuals who suffered repeated pregnancy losses were 8 weeks in age $7(11.67 \%), 8-16$ weeks in 10 $(16.67 \%), 16-22$ weeks in 4 weeks (6.67 percent) ${ }^{3}$. The diagnosis of hypothyroidism in pregnancy is complicated, given that most clinical signs are unspecific (asthenia, lethargy) or may conceal obstetric symptoms (increase in weight, altered appetite). The different clinical grading systems mentioned here only apply to non-pregnant persons and cannot be applied in the prenatal ambulatory department ${ }^{4}$. Pregnancy impacts the thyroid economy, which has major alterations in iodine metabolism, serum thyroid-binding proteins and maternal goitre development, particularly in areas of iodine deficiency. Before and during pregnancy the thyroid gland and gonadal axis interact continually. Hypothyroidism impacts the function of the ovary by lowering sex hormone-binding globulin levels and boosting prolactin production ${ }^{5}$. Although the RPL diagnosis can be rather disappointing, it can be helpful for the doctor and the patient to take into consideration the fairly high probability of success in the following pregnancy. The prognosis of a given person depends on both the underlying cause of the loss of pregnancy and the number of previous losses. The highest success rates of endocrine problems, APAs and anatomical malformations are around $60 \%$ to $90 \%$. Patients with a cytogenetic basis for loss have a variety of successes (20\%-80\%) that depend on the type of abnormality ${ }^{6}$. The potential value of any screening technique depends heavily on the relative contribution of thyroid dysfunction to negative pregnancy results and the effects of treatment ${ }^{7}$. In one of the local studies, 262 women were tested for thyroid function while investigating the loss of pregnancy. In $11.45 \%$ of women $^{8}$, overt 
hypothyroidism was observed in subclinical and undiagnosed cases8. In patients with recurrent abortions and unexplained dead birth, a significant suspicion of hypothyroidism should be found. During pregnancy and intrapartum, careful monitoring and control of hypothyroidism is important since these individuals are more likely to develop PIH, GDM and foetal distress on labour ${ }^{9}$.

The purpose of this study is to assess the hypothyroidism frequency in recurring pregnancy loss and to decide if universal testing of pregnant women is required for a hypothyroidism, and treatment of the disease can lower the cost of adversely affected foetal and mother outcomes.

\section{MATERIAL AND METHODS}

This cross sectional study was conducted at Obstetrics and Gynaecology department of Dow Medical University \& Hospital, Ojha Campus, Karachi, from $7^{\text {th }}$ July 2018 to $6^{\text {th }}$ July 2019. The samples were taken using Non-Probability consecutive technique, detailed history with special regard to demographics like age, parity and recurrent pregnancy loss was taken from all the patients after taking patient's informed written consent. All pregnant female was between age 20-35 years with $\geq 6$ months gestational age and history of parity 3 and gravida 4 were included in the study. Patients with Known case of hypothyroidism or history of taking medication for hypothyroidism, patient with history of Hypertension and DM were excluded from this study. After collection of data the analyses were conducted by using Statistical Package for Social Science (SPSS) software, Version 16. Mean and standard deviation were calculated for quantitative variables like age. Frequency and percentages were computed for qualitative variables like parity and hypothyroidism.

\section{RESULTS:}

There was wide variation of age ranging from a minimum of 20 years to 35 years. The mean age was $28.4 \pm 4.49$ years and mostly patients were parity 3 and gravid 4 in $55(66.26 \%)$ cases followed by parity 4 and gravid 4 in $28(33.73 \%)$ cases. In our study mostly patients were parity 3 and gravid 4 in 55(66.26\%) cases followed by parity 4 and gravid 4 in $28(33.73 \%)$ cases. Table 1

Table 1: mean age, parity and gestational age of patients.

\begin{tabular}{|l|l|l|}
\hline Variable & Frequency & percentage \\
\hline Mean Age & $28.4 \pm 4.49$ & \\
\hline Parity & & $33.73 \%$ \\
\hline 3 & & $66.26 \%$ \\
\hline 4 & \multicolumn{2}{|l|}{} \\
\hline Gestational Age & 13 & $15.66 \%$ \\
\hline 8 Weeks & 41 & $49.39 \%$ \\
\hline $9-16$ Weeks & 29 & $34.93 \%$ \\
\hline $17-22$ Weeks &
\end{tabular}

Patient's mean Thyroid-stimulating hormone (TSH) level was $2.39 \pm 1.66 \mathrm{mU} / \mathrm{L}$, mean free $\mathrm{T} 4$ was $17.23 \pm 6.41$ $\mathrm{nmol} / \mathrm{L}$ and mean free T3 was $4.87 \pm 1.18 \mu \mathrm{mol} / \mathrm{L}$. (Table 2 )
Table 2: Thyroid Profile

\begin{tabular}{|l|l|l|}
\hline THYROID PROFILE & $\begin{array}{l}\text { CONTROL } \\
\text { VALUES }\end{array}$ & RESULT \\
\hline $\begin{array}{l}\text { Thyroid-stimulating } \\
\text { hormone (TSH) level }\end{array}$ & $0.3-3.3 \mathrm{mU} / \mathrm{L}$ & $\begin{array}{l}2.39 \pm 1.66 \\
\mathrm{mU} / \mathrm{L}\end{array}$ \\
\hline free T4 & $10-30 \mathrm{nmol} / \mathrm{L}$ & $\begin{array}{l}17.23+6.41 \\
\mathrm{nmol} / \mathrm{L}\end{array}$ \\
\hline free T3 & $3.5-7.5 \mu \mathrm{mol} / \mathrm{L}$ & $\begin{array}{l}4.87 \pm 1.18 \\
\mu \mathrm{mol} / \mathrm{L}\end{array}$ \\
\hline
\end{tabular}

Hypothyroidism was observed in $11(13.3 \%)$ cases while rest of $72(86.7 \%)$ cases within normal range. (Chart 1 )

Chart 1: Thyroid Dysfunction in Pregnancy

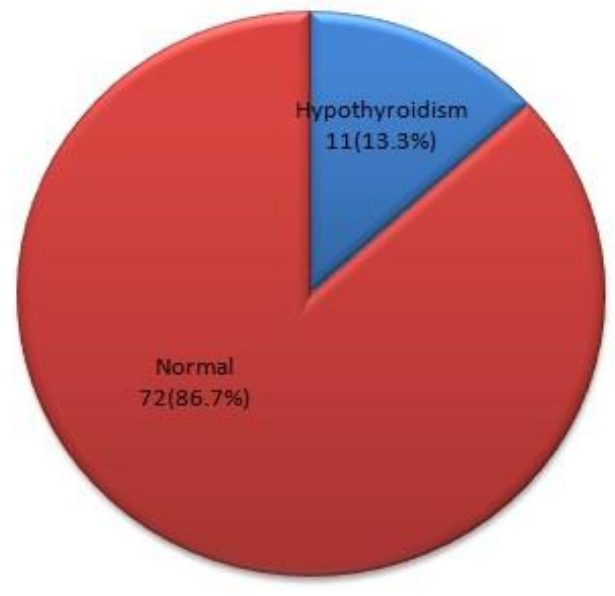

\section{DISCUSSION}

$\mathrm{H}$ Hypothyroidism is a disorder that has an impact on both the mother and the fetus's result. The intellectual development of children born to untreated or undertreated moms has a significant impact on their future [10]. Pregnancy is associated with reversible alterations in the physiology of the mother's thyroid gland. The thyroid gland has had a mild hypertrophy. There is a rise in the levels of thyroid binding globulin, which is a hormone-mediated response. The thyroid is stimulated as a result of the "spill effect" caused by HCG, which has structural similarities to thyroid stimulating hormone (TSH). Increased renal clearance, as well as losses to the foetus and placenta, have all contributed to a relative drop in the availability of iodine [11].

Maternal age varied widely in our study, ranging from 20 years to 35 years, with a minimum of 20 years and a maximum of 35 years. In this study, the mean age was 28.4+ 4.49 years. In contrast, Dinesh K. Dhanwal's study found that the mean (standard deviation) maternal age of the patients was $25.6+11.1$ years. Similarly, this is likely to be the case [13].

As a result, the incidence is approximately twice what would have been predicted by chance alone, indicating that an anomaly is most certainly present. The risk of miscarriage increases with the stage of pregnancy, with the majority of miscarriages happening in the first trimester [14]. In our study, ultrasonography was used to determine the gestational age, which ranged from 8 weeks to 22 weeks. Pregnancy began at a mean gestational age of $14.20+4.71$ years. 
In our study, we found 11 (13.3 percent) of the women had hypothyroidism, which is a condition in which women have no symptoms but have abnormal TSH levels on clinical biochemistry. We did not find many studies that demonstrated a link between subclinical hypothyroidism and recurrent pregnancy loss, but we did find one that did. Patients who have experienced recurrent pregnancy loss should be offered treatment in order to avoid errors during pregnancy [15]. Based on the work of thyroid associations, a proposal was developed in 2007 that addresses disease of the thyroid gland in pregnancy, detection of the illness, and treatment of the illness [16]. However, in a country like ours with limited resources and patients who are unaware of their own hypothyroidism, it may be difficult to bring all of the patients into the clinic for further evaluation.

Patient's mean Thyroid-stimulating hormone (TSH) level was $2.39 \pm 1.66 \mathrm{mU} / \mathrm{L}$, mean free $\mathrm{T} 4$ was $17.23 \pm 6.41$ $\mathrm{nmol} / \mathrm{L}$ and mean free T3 was $4.87 \pm 1.18 \mu \mathrm{mol} / \mathrm{L}$. However the study Of Shrestha A Chawla reported that 103 women with recurrent pregnancy loss, thirtyeight (36.89\%) of them had high level of TSH. Amongst these $23(22.33 \%)$ had levels more than $10 \mathrm{mU} / \mathrm{L}, 15(14.56 \%)$ of them had TSH within the range of $7-10 \mathrm{mU} / \mathrm{L}$ [17]. Another study reported that the mean value of fT3 in aborts group was $4.25 \pm 1.87$ $\mathrm{pmol} / \mathrm{l}$, and in control group it was $5.116 \pm 1.705 \mathrm{pmol} / \mathrm{l}$. Thus fT3 was significantly lower in aborts group as compared to control group. Decrease in fT3 level was found to be statistically highly significant $(P<0.05)$. The mean fT4 value in aborts and control group was $14.77 \pm 6.19$ $\mathrm{pmol} / \mathrm{l}$ and $17.099 \pm 5.028 \mathrm{pmol} / \mathrm{l}$ respectively. Thus fT4 was significantly lower in cases as compared to control group. This decrease in fT4 level was found to be statistically highly significant $(\mathrm{P}<0.05)$. Mean $\mathrm{TSH}$ value in aborts group was $10.024 \pm 4.13 \mu \mathrm{lU} / \mathrm{L}$ and in control group it was $7.658 \pm 3.114 \mu \mathrm{IU} / \mathrm{L}$. Thus mean $\mathrm{TSH}$ value was significantly higher in aborts as compared to control group with $(\mathrm{P}<$ 0.001 ) [18].

Hypothyroidism is the most frequent thyroid gland abnormality that occurs during pregnancy. It is estimated that 1.5 percent to 4.4 percent of pregnant women are affected by this condition [19 and 20]. Women who suffer from hypothyroidism have a lower chance of becoming pregnant. Hypothyroidism is caused mostly by insufficient intake and availability of iodine in Nepal, which is the country's most populous country. Hypothyroidism can be caused by a variety of factors, including thyroid surgery, autoimmune thyroiditis, and radioactive iodine treatment. When a woman with hypothyroidism conceives, she may experience complications such as spontaneous abortions, premature birth, placental abruption, and irreversible damage to the foetus, such as failure of nerve differentiation, inadequate central nervous system development, and an increased risk of prenatal death due to ovulatory dysfunction [21, 22]. When thyroid cancer is detected and treated early [24], these significant effects can be avoided or at least reduced in severity. Women who have recurrent pregnancy loss may benefit from having their thyroid function checked, and medication may have a positive impact on pregnancy outcome, according to our research.

Amit $R$. Barapatre reported that incidence of thyroid dysfunction in form of hypothyroidism was found to be $35 \%$ i.e. 21 out of 60 cases of recurrent spontaneous abortions. All of these 21 cases showed the overt clinical hypothyroidism [18]. While in our study observed hypothyroidism was in $11(13.3 \%)$ cases while rest of $72(86.7 \%)$ cases within normal range. Another study conducted by V. Ramachandra, A. Laksmi et al (2008) observed the hypothyroidism in $4.29 \%$ cases as cause of recurrent pregnancy loss. Thus they concluded that hypothyroidism had statistically significant relation-ship with recurrent pregnancy loss in first trimester and diagnosis of hypothyroidism could help couples with recurrent pregnancy loss to have a successful outcome in subsequent pregnancies [23].

\section{CONCLUSION}

Our study concluded that hypothyroidism is problem in recurrent pregnancy loss. $11(13.3 \%)$ cases Frequency of hypothyroidism in women with pregnancy, the possible role of thyroid functional disorders in etiology of at least some part of recurrent pregnancy loss, had emphasized the importance of thyroid functions tests screening as routine in all pregnancies.

We propose the inclusion of serum TSH as screening test for hypothyroidism during pregnancy. There should be a high index of suspicion for hypothyroidism in patients with recurrent pregnancy loss. Careful monitoring \& control of hypothyroidism during pregnancy \& intrapartum period is necessary. Hence routine TSH should be evaluated as a way to potentially improve pregnancy outcome \& maternal wellbeing.

\section{REFERENCES}

1. Sahay RK, Nagesh VS. Hypothyroidism in pregnancy. Indian J Endocr Metab. 2012;16:364-70.

2. Rao RC, Lakshmi A, Sadhnani MD. Prevalence of hypothyroidism in recurrent pregnancy loss in first trimester . Indian J Med Sci. 2008;62(9):357-361.

3. Barapatre AR, Vaidya S. Study of thyroid proile in patients of recurrent abortions. J Evolution Med Dental Sci. 2013;I2(49):9614-9620.

4. Sahay R, Kalra S, Magon N. Ensuring an intelligent India: Managing hypothyroidism in pregnancy. Indian J Endocrinol Metabol. 2011;15(2):76-7.

5. Mannisto T, Vaarasmaki M, Pouta A, Hartikainen Al, Ruokonen A, Surcel HM, et al. Thyroid dysfunction and maternal morbidity. J Clin Endocrinol Metab. 2012;95:108494.

6. Ford HB, Schust DJ. Recurrent Pregnancy Loss: Etiology, Diagnosis, and Therapy. Rev Obstet Gynecol. 2009;2(2):7683.

7. Boogaard E, Vissenberg R, Land JA, Wely M, Joris AM, Goddijn $M$, et al. Significance of (sub)clinical thyroid dysfunction and thyroid autoimmunity before conception and in early pregnancy: a systematic review. Human Reproduction Update. 2011;17(5):605-19.

8. Khalid AS, O'Donoghue K. Pregnancy outcome. Hypothyroidism and pregnancy loss: how significant is it? Arch Dis Child Fetal Neonatal Ed. 2010;95:35-40.

9. Goel P, Radotra A, Devi K, Malhotra S, Aggarwal A, Huria A. Maternal and perinatal outcome in pregnancy with hypothyroidism. Indian J Med Sci. 2005;59(3):116-7

10. Dhanwal DK, Prasad S, Agarwal AK, Dixit V, Banerjee AK. High prevalence of subclinical hypothyroidism during first trimester of pregnancy in North India. Indian $\mathrm{J}$ Endocrinol Metab. 2013;17:281-284. 
11. Brain M. Thyroid disease in pregnancy. Obstetrics and gynecology 2006;108:1283-1292.

12. Dhanwal DK, Prasad S, Agarwal AK, Dixit V, Banerjee AK High prevalence of subclinical hypothyroidism during first trimester of pregnancy in North India .Indian J Endocrinol and Metabolism. Mar-Apr 2013;17(2):281-4.

13. Niekerk EC, Siebert I, Kruger TK, An evidence-based approach to recurrent pregnancy loss. S Afr J OG 2013;19(3):61-65. DOI:10.7196/SAJOG.670.

14. Negro R, Schwartz A, Gismondi R, Tinelli A, Mangieri $T$, Stagnaro-Green $A$. Increased pregnancy loss rate in thyroid antibody negative women with TSH levels between 2.5 and 5.0 in the first trimester of pregnancy. J Clin Endocrinol Metab. 2010;95(9):E44-8.

15. Abalovich $M$, Amino $N$, Barbour LA, Cobin RH. A management of thyroid dysfunction during pregnancy and postpartum: an endocrine society clinical practice guideline. J Clin Endocrinol Metab. 2007;92(8Suppl):S1-47.

16. Shrestha A, Chawla CD Abnormal Thyroid Function and Recurrent Pregnancy Loss.NJOG 2014 Jan-Jun;17(1):29-32.
17. Barapatre AR, Vaidya S. Study of thyroid proile in patients of recurrent abortions. J Evolution Med Dental Scien 2013;12(49):9614-9620.

18. Lazarus JH, Premawardha LD. Screening for thyroid disease in pregnancy. J Clin Pathol. 2005;58(5):449-52.

19. Horacek J, Spitalnikova S, Dlabalova B, Malirova E, Vizda J, Svilias I, et al. Universal screening detects two-times more thyroid disorders in early pregnancy than targeted high-risk case finding. Eur J Endocrinol. 2010;163(4):645- 50.

20. Poppe K, Velkeniers B, Glinoer D. The role of thyroid autoimmunity in fertility and pregnancy. Nat Clin Pract Endocrinol Metab. 2008;4:394-405.

21. Moralle de Escobar G, Escobar F. Maternal thyroid hormones early in pregnancy and fetal brain development. Best Pract Res Clin Endocriniol Metab. 2004;18:225-48.

22. Say RK, Nagesh VR. Hypothyroidism in pregnancy. Indian J Endocrinol Metab. 2012;16(3): 364-70. 